\title{
Heavy Metals Adsorption from Aqueous Solutions onto Unmodified and Modified Jordanian Kaolinite Clay: Batch and Column Techniques
}

\author{
Khansaa Al-Essa ${ }^{1, ~ *, ~ F a w w a z ~ K h a l i l i ~}$ \\ ${ }^{1}$ Chemistry Department, Jerash University, Jerash, Jordan \\ ${ }^{2}$ Chemistry Department, University of Jordan, Amman, Jordan \\ Email address: \\ k.essa@jpu.edu.jo (K. Al-Essa), khansaa.essa@gmail.com (K. Al-Essa) \\ ${ }^{*}$ Corresponding author
}

To cite this article:

Khansaa Al-Essa, Fawwaz Khalili. Heavy Metals Adsorption from Aqueous Solutions onto Unmodified and Modified Jordanian Kaolinite Clay: Batch and Column Techniques. American Journal of Applied Chemistry. Vol. 6, No. 1, 2018, pp. 25-34.

doi: 10.11648/j.ajac.20180601.14

Received: December 16, 2017; Accepted: January 6, 2018; Published: January 18, 2018

\begin{abstract}
Awareness of, and concern about, water pollution all over the world has been increasing. In Jordan, water also has been polluted by different kinds of pollutants such as heavy metals, It is widely agreed that a properly developed green, low cost and more efficient adsorbent is desired approach towards removing pollutants. Jordan has huge reserves of kaolinite. Unfortunately, it has a relative low cation-exchange capacity and a small-surface area. However, it can be modified to enhance its adsorption capacity towards heavy metal ions. Humic acid was used to this purpose. Two types of humic acid were used; one was commercial from Fluka Company and the other was natural extracted from King Talal Dam sediments. Comparison of $\mathrm{Pb}$ (II), $\mathrm{Cd}$ (II) and $\mathrm{Zn}$ (II) adsorption from aqueous solutions onto unmodified and modified Jordanian kaolinite clay were studied using batch technique at different temperatures $\left(25,35\right.$ and $\left.45^{\circ} \mathrm{C}\right)$ and different $\mathrm{pH}(4,5$ and 6$)$. The effects of contact time, adsorbent dose, and the initial metal ion concentration were also studied. The uptake at low concentration reaches above $90 \%$ for $\mathrm{Pb}$ (II). The adsorbed amount trend was as follows: $\mathrm{Pb}$ (II) $>\mathrm{Cd}$ (II) $>\mathrm{Zn}$ (II) for both modified kaolinite clay. The column technique was used effectively for the determination of metal ion loading capacity. The uptake percentage fall in the same order ( $\mathrm{Pb}$ (II) $>\mathrm{Cd}$ (II) > Zn (II)) for both modified kaolinite clay.
\end{abstract}

Keywords: Heavy Metal Ions, Adsorption Isotherms, Humic Acid, Jordanian Kaolinite, Batch Technique, Column Technique

\section{Introduction}

Kaolinite, $\left(\mathrm{Si}^{\mathrm{IV}}\right)_{4}\left(\mathrm{Al}^{\mathrm{III}}\right)_{4} \mathrm{O}_{10}(\mathrm{OH})_{8}$, is the most common two-sheet type clay mineral layer. Its formula indicates that there is no substitution of $\mathrm{Si}^{4+}$ with $\mathrm{Al}^{3+}$ in the tetrahedral layer and no substitution of $\mathrm{Al}^{3+}$ with other ions (e.g., $\mathrm{Mg}^{2+}, \mathrm{Zn}^{2+}$, $\mathrm{Fe}^{2+}, \mathrm{Ca}^{2+}, \mathrm{Na}^{+}$or $\mathrm{K}^{+}$) in the octahedral layer. Thus, the net layer charge of kaolinite is zero. But in nature, kaolinite has a small net negative charge arising on the clay crystals due to protonation/deprotonation influenced by the solution $\mathrm{pH}$. This negative charge, although small, is responsible for the surface not being completely inert; it allows electrostatic interaction with positively charged ions [1].

Typically, kaolinite has a relative low cation-exchange capacity (CEC) of 3-15 meq/100 g of clay and a small-surface area ranging from $10-20 \mathrm{~m}^{2} / \mathrm{g}[2,3]$. It can however be modified from its natural state by physical or chemical treatment to improve its sorption capacity. It was shown that the reactive edge sites of kaolinite may be coated with adsorbed organic matter, enhancing thus further its metal ion adsorption capacity [4]. Moreover, Kaolinite coated with humic substances play an important role in the environmental behavior of various ions [5].

Humic acid (HA) is a complex aggregate of dark-colored amorphous high molecular weight substances extracted from the natural degradation products of plant and animal residues. Although a considerable work on HA can be found in literature, only a few of them have dealt with the adsorption of 
HA on clay minerals. HA is completely soluble only in strong basic solutions. Its solubility increases with increasing $\mathrm{pH}$ [6].

Several mechanisms are involved in the adsorption of humic substances by clay minerals, the main ones being van der Waals forces (bonding by cation bridging) and $\mathrm{H}-$ bonding. The Al-OH tetrahedral in the clay mineral phase may interact via $\mathrm{H}$ bonds with $\mathrm{Ar}-\mathrm{OH},-\mathrm{COOH}$ and alcohol groups in HA's resulting in the surface binding or occlusion of organic carbon within the clay matrix and adsorption on the interlamellar spaces of clay minerals [4].

Methods used for the removal of heavy metal ions are chemical precipitation, ion exchange, solvent extraction, reverse osmosis and adsorption [7]. The process of adsorption has become one of the preferred methods for the removal of toxic contaminants from water as it has been found to be very effective, economical, versatile and simple. Adsorption has the additional advantages of applicability at very low concentrations, suitability for being used in batch and continuous processes. Adsorption has acquired global importance for the minimization of water and air contamination. Also, its significant addition to Green Chemistry endeavors [8].

A number of studies concerning kaolinite clay used to remove heavy metal ions from aqueous solution have been reported. Kaolinite and metakaolinite obtained from Cameroon were used as adsorbents to study their adsorptive capacities on the removal of zinc (II) ions. The maximum adsorption took place at $\mathrm{pH}=8.5$ for the two adsorbents. With the adsorbent mass of $0.05 \mathrm{~g}$, the quantities adsorbed of 7.196 and 12.375 $\mathrm{mg} / \mathrm{g}$ were recorded for kaolinite and metakaolinite respectively. The adsorption isotherm of zinc (II) ions on the kaolinite was a physisorption process, whereas on the metakaolinite, the process was chemisorption. The kinetic studies showed that the adsorption of zinc (II) ions on the kaolinite and metakaolinite followed the pseudo-second order equation [9]. Modified kaolinite was also tested; Thio- kaolinite nanohybrid adsorbent was obtained by grafting the compound 3,6 - dithia - 1,8 octanediol $\left(\mathrm{HO}\left(\mathrm{CH}_{2}\right)_{2} \mathrm{~S}\left(\mathrm{CH}_{2}\right)_{2} \mathrm{~S}\left(\mathrm{CH}_{2}\right)_{2} \mathrm{OH}\right)$ onto the internal aluminol surfaces of both the urea- and dimethylsulfoxide (DMSO) precursors of two sources of kaolinite clay. The potential application of these adsorbents as a heavy metal adsorbents was tested in $\mathrm{ZnCl}_{2}$ solutions as well as in zinc-spiked raw wastewater. Variable adsorption capacities of the different kaolinite samples were demonstrated, and a consistently greater zinc removal in the wastewater system compared to simple zinc solutions [10].

Another study of a bifunctional Ti-Fe kaolinite composite was used as an adsorbent as well as photocatalyst for Cr (VI) removal. The results indicate that the low $\mathrm{pH}$ is favorable to the $\mathrm{Cr}$ (VI) removal and the removal rate of $\mathrm{Cr}$ (VI) reached $87 \%$ at $\mathrm{pH} 3.0$. Visible light irradiation obviously increased the removal of $\mathrm{Cr}$ (VI) by the composite and greatly shortened reaction equilibrium time, which may be attributed to the photocatalytic reduction of $\mathrm{Cr}$ (VI) to $\mathrm{Cr}$ (III) by $\mathrm{TiO}_{2}$ associated with simultaneous redox cycle of $\mathrm{Fe}$ (III)/Fe (II). The composite exhibited very high stability for the $\mathrm{Cr}$ (VI) removal [11].
Jordan has huge reserves of kaolinite spread throughout the country [12]. On the other hand, the greatest environmental challenge that Jordan faces today is the scarcity of water; Jordan has one of the lowest levels of water resources in the world [13]. In addition, water in Jordan has been polluted by different kinds of pollutants such as heavy metals [14].

This study aims at introducing Jordanian kaolinite clay modified by HA as a new low - cost and more efficient adsorbent. Adsorption isotherm of heavy metals on kaolinite clay modified by two types of HA's will be studied at different $\mathrm{pH}$ and temperatures to understand its nature.

\section{Materials and Methods}

\subsection{Chemicals}

All chemicals were obtained from commercial sources as either analytical reagent grade or chemically pure grade and were used as received. The chemicals were purchased from the corresponding companies: sodium perchlorate $\left(\mathrm{NaClO}_{4}\right)$ (Acros), lead (II) nitrate; ( $\left.\mathrm{Pb}\left(\mathrm{NO}_{3}\right)_{2}\right)$ (PRS Paureac), cadmium (II) nitrate tetrahydrate; $\left(\mathrm{Cd}\left(\mathrm{NO}_{3}\right)_{2} \cdot 4 \mathrm{H}_{2} \mathrm{O}\right)(\mathrm{BDH})$, zinc nitrate hexahydrate; $\left(\mathrm{Zn}\left(\mathrm{NO}_{3}\right)_{2} \cdot 6 \mathrm{H}_{2} \mathrm{O}\right)(\mathrm{BDH})$, sodium hydroxide $\mathrm{NaOH}$ (LOBA), hydrochloric acid; $\mathrm{HCl} 37 \%$ (TEDIA), potassium chloride; $\mathrm{KCl}$ (Puriss), ethylenediaminetetraacetate-disodium salt $\left(\mathrm{EDTANa}_{2}\right)$, silver nitrate; $\mathrm{AgNO}_{3}$ (Puriss). Two types of HA were used. One was commercial from Fluka Company (FHA) and the other was natural extracted from King Talal Dam (KTD) sediments (The King Talal Dam, built in 1978 on the Az Zarqa River, formed Jordan's major reservoir) [15]. Kaolinite clay was obtained from the Azraq region in the east of Jordan.

\subsection{Instrumentation}

Concentrations of the metal ions were determined using atomic absorption spectrometer (AAS) (Varian Spectra AA250 pulse). Concentrations of HA acid were determined using UV-VIS spectrophotometer (Varian cary 100). Drying of modified kaolinite clay was performed in an Alpha 1-4 freezedryer (ALPHA 1-4). The samples were shaken using a Clifton Shaker equipped with thermostat and the $\mathrm{pH}$ was measured using a METROHM $605 \mathrm{pH}-$ meter. The surface area of kaolinite clay was measured using a (Gemini VII) instrument from Micromeritics. The porosity of kaolinite clay was measured using a Mercury Porosimetry Analyzer instrument (Model: PM-60-13) from Quantachrome Instruments.

\subsection{Methods}

\subsubsection{HA-Kaolinite Clay Complex Preparation}

To prepare HA modified kaolinite clay, same method used by $\mathrm{Li}$ et al., was followed [16]. $1000 \mathrm{mg} \pm 0.1 \mathrm{mg}$ of either FHA or KTD was dissolved in $1.0 \mathrm{~L}$ of $0.5 \mathrm{M} \mathrm{KCl}$ solution at $\mathrm{pH} 4$ and $45^{\circ} \mathrm{C}$, followed by mixing with $10 \mathrm{mg} \pm 0.1 \mathrm{mg}$ of the corresponding $\mathrm{K}^{+}$-kaolinite for 1 week. The HA-kaolinite adduct was separated by centrifugation, and mixed with $0.5 \mathrm{M}$ $\mathrm{KCl}$ solution (three times) to saturate the cation-exchange 
sites in HA, and then dialyzed against deionized water and washed (twenty times) with deionized water until neither light brown-colored humic substances in supernatants nor HA particulates accumulating on the top of kaolinite fractions after centrifugation were visualized. The HA-kaolinite complex was quickly frozen and freeze-dried.

The prepared HA- kaolinite clay complex is well characterized by authors; the obtained results showed a strong stable formation of modified kaolinite complex [17].

\subsubsection{Preparation of Stock Solutions of Metal Ions}

Stock solutions of $100 \mathrm{ppm}$ for each metal ion were prepared separately by dissolving separately a specific amount of $\mathrm{Pb}$ (II), $\mathrm{Cd}$ (II) and $\mathrm{Zn}$ (II) nitrate in $0.01 \mathrm{M} \mathrm{NaClO}$ and was adjusted by $0.10 \mathrm{M} \mathrm{HCl}$ and/or $0.10 \mathrm{M} \mathrm{NaOH}$ to the desired $\mathrm{pH}$. The stock solutions were used to prepare solutions with different concentrations $(10,20,30,40,50,60,80$ and $100 \mathrm{ppm}$ ). The $0.01 \mathrm{M} \mathrm{NaClO}_{4}$ was used to keep the ionic strength constant.

\subsubsection{The Rate of Metal Ions Uptake in Batch Mode}

Experiments for determining the time needed to reach adsorption equilibrium were carried out by shaking $200 \mathrm{mg} \pm$ $0.1 \mathrm{mg}$ of the modified kaolinite clay with $20.0 \mathrm{~mL}$ of 100 ppm metal ion solution at a $\mathrm{pH}$ value of 5 . The contact time was varied from 30 minutes to 24 hours at $35^{\circ} \mathrm{C}$. The mixture was filtered and the concentration of the metal ion remaining was determined using AAS. Each measurement was done three times to ensure accuracy and reproducibility of the results.

The effect of $\mathrm{pH}$ on the metal ions uptake was also studied, similar experiments were carried out, but under different $\mathrm{pH}$ values of 4, 5 and 6 and at fixed contact time of 4 hours.

\subsubsection{Adsorption Isotherms Experiments}

The adsorption of $\mathrm{Pb}$ (II), Cd (II) and $\mathrm{Zn}$ (II) was carried out by taking $200 \mathrm{mg} \pm 0.1 \mathrm{mg}$ of the modified kaolinite clay with $20.0 \mathrm{~mL}$ of solutions of various metal ion concentrations ranging between 10-100 ppm for each metal at different $\mathrm{pH}$ values $(4,5$ and 6$)$ and at different temperatures $(25,35$ and $45^{\circ} \mathrm{C}$ ). The metal ion uptake by the kaolinite clay (q) was obtained using the following equation:

$$
\mathrm{q}=\frac{\left(\mathrm{C}_{\mathrm{i}}-\mathrm{C}_{\mathrm{e}}\right)}{\mathrm{m}} \mathrm{V}
$$

Where;

q: Metal ion uptake by kaolinite clay in (mg metal ion (II)/ g kaolinite).

$\mathrm{C}_{\mathrm{i}}$ : Initial metal ion concentration (ppm) in the solution.

$\mathrm{C}_{\mathrm{e}}$ : The remaining concentration of the metal ion in solution at equilibrium (ppm).

$\mathrm{V}$ : volume of solution (L).

$\mathrm{m}$ : mass of kaolinite clay $(\mathrm{g})$.

The percentage of metal ion loading by the kaolinite clay expressed as $\%$ uptake where

$$
\% \text { Metal uptake }=\frac{\left(C_{i}-C_{e}\right)}{C_{i}} \times 100[18]
$$

\subsubsection{Metal Ions Uptake by the Column Mode}

a. Adsorption experiments

A $30 \mathrm{~cm}$ long glass column with $20 \mathrm{~mm}$ inner diameter was used to adsorb $\mathrm{Pb}$ (II), Cd (II) and Zn (II) from solution. The column was packed with $2000 \mathrm{mg} \pm 0.1 \mathrm{mg}$ of dried modified kaolinite clay. $100.0 \mathrm{~mL}$ of $100 \mathrm{ppm}$ of each metal ion solutions ( $\mathrm{pH} 4)$ was divided into ten portions $(10.0 \mathrm{~mL}$ each) and passed through the column. The eluent was collected in ten test tubes. And the remaining concentration of the metal ion in each test tube was determined using AAS.

b. Desorption and regeneration experiments

The desorption of the $\mathrm{Pb}$ (II), Cd (II), and $\mathrm{Zn}$ (II) ions was carried out on a column loaded with each metal ion as described in the previous section. The column was then eluted using $0.1 \mathrm{M} \mathrm{HNO}_{3}$ for $\mathrm{Pb}$ (II) and $\mathrm{Cd}$ (II), and $1 \mathrm{M}$ EDTA for $\mathrm{Zn}$ (II), while keeping the flow rate of elution at $1.0 \mathrm{~mL} / \mathrm{min}$. The eluate was collected in four portions $(10.0 \mathrm{~mL}$ each) and the concentration of metal ions in each portion was determined using AAS.

The regenerated modified kaolinite clay was reloaded with $20.0 \mathrm{~mL}$ of $1000 \mathrm{ppm}$ and metal ion solutions ( $\mathrm{pH} 4)$ which were divided into two portions $(10.0 \mathrm{~mL})$ and was passed through the column at $1.0 \mathrm{~mL} / \mathrm{min}$ flow rate. The eluent was collected in two test tubes. And the concentrations of the metal ion in each test tube were determined using AAS. Every measurement was made three times to ensure accuracy and reproducibility of the results.

\section{Results and Discussion}

\subsection{Adsorption of Heavy Metal Ions onto Kaolinite Clay by Batch Technique}

\subsubsection{Unmodified Kaolinite Clay}

a. Effect of contact time

The effect of contact time on the adsorption of $\mathrm{Pb}$ (II), $\mathrm{Cd}$ (II) and $\mathrm{Zn}$ (II) was shown in Figure 1, the equilibrium adsorption was established within 4 hours, indicating that the initial adsorption was very fast and the maximum uptakes recorded within the equilibrium period; at which the $\%$ uptake of metal ion is constant.

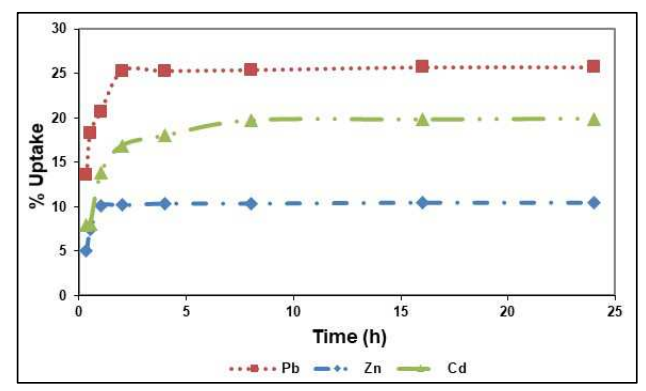

Figure 1. Effect of contact time on the amount of adsorption of Pb (II), Cd (II) and $\mathrm{Zn}$ (II) by unmodified kaolinite clay. Initial concentration of metal ion is 100 ppm and temperature is $35^{\circ} \mathrm{C}$. 
The removal capacity for different metal ions on the kaolinite clay was determined to be in the order of $\mathrm{Pb}$ (II) $>\mathrm{Cd}$ (II) $>\mathrm{Zn}$ (II).

In general, the most important factors that influence the relative selectivity of metal ions in solution are their valence and ionic radii [19]. From comparison of the three elements studied, lead (II) ion has the largest ionic radius. If metal adsorption on the kaolinite clay were entirely electrostatic, ions with a larger ionic radius should be adsorbed more strongly $[20,21]$. The ionic radius order is $\mathrm{Pb}$ (II) $>\mathrm{Cd}$ (II) $>$ $\mathrm{Zn}$ (II). Furthermore, the selectivity sequence of adsorption observed to be: $\mathrm{Pb}$ (II) $>\mathrm{Cd}$ (II) $>\mathrm{Zn}$ (II).

Another factor that has an effect is the hydration energy. The hydration energy values decrease as the ionic radius increases [22], and the values increase as the hydration shell increases. The metal with the highest hydration energy should therefore prefer to remain in the solution phase. The formation of an aqua complex $\left[\mathrm{M}\left(\mathrm{OH}_{2}\right)_{\mathrm{m}}\right]^{\mathrm{n}+}$ takes place where $\mathrm{m}$ is larger than six. The aqua complex, having $\mathrm{m} \mathrm{H}_{2} \mathrm{O}$ molecules surrounding the central metal ion, has a definite structure and the cloud of water molecules (hydration shell) has a different local structure than the rest of the water. A stronger hydration shell will surround a metal ion with a smaller radius, than the metal ion with a larger radius. Thus, the adsorptivity of an ion with a larger radius is higher than that of a small radius ion [23]. The hydration energy of $\mathrm{Pb}$ (II) is the smallest of three cations, so $\mathrm{Pb}$ (II) most easily lose water ligands and become the bare $\mathrm{Pb}$ (II) when it adsorbed into modified kaolinite.

b. Effect of $\mathrm{pH}$

The adsorption of $\mathrm{Pb}$ (II) ions on kaolinite clay was found to increase with increasing $\mathrm{pH}$ (Figure 2). Several reasons may be attributed to the increased adsorption of $\mathrm{Pb}$ (II) ions by unmodified kaolinite. The surface of the kaolinite clay sample contains some active sites which may become positively charged at low $\mathrm{pH}$ [24]. Hence, the positive charge on the kaolinite surface was $\mathrm{pH}$ dependent, increasing with decreasing $\mathrm{pH}$ values. $\mathrm{Al}-\mathrm{O}-\mathrm{H}_{2}^{+}$will be present [25]. This increases the competition between $\mathrm{H}^{+}$and the metal ions for available adsorption sites. However, as $\mathrm{pH}$ increases, this competition decreases as these surface active sites becomes neutral and/or more negatively charged, which enhances the adsorption of the positively charged metal ions through electrostatic force of attraction.

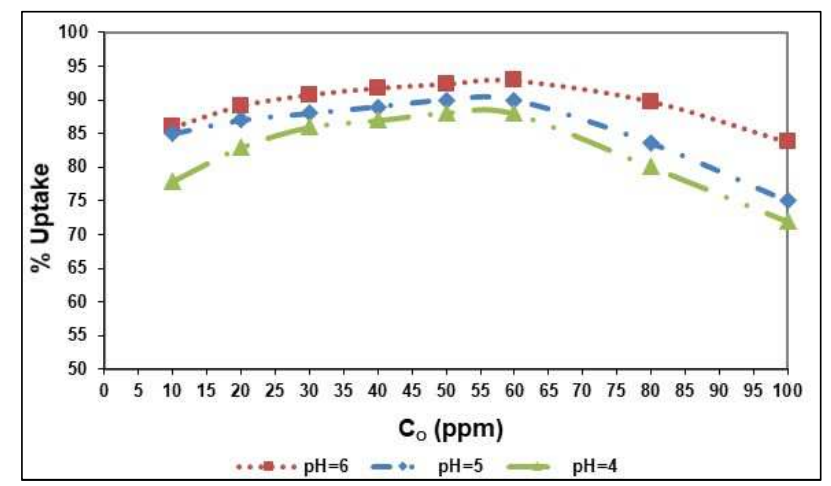

Figure 2. Effect of $p H$ on the adsorption of $\mathrm{Pb}$ (II) onto unmodified kaolinite clay at $35^{\circ} \mathrm{C}$.
The adsorption experiment was carried out with initial $\mathrm{pH}$ range $4-6$, at $35^{\circ} \mathrm{C}$ for $(0.1 \mathrm{~g} \pm 0.1 \mathrm{mg})$ adsorbent dose and 10.0 $\mathrm{mL}$ of different initial concentrations $10-100 \mathrm{ppm}$ of $\mathrm{Pb}$ (II). At this constant adsorbent dose, the maximum $\%$ uptake of $\mathrm{Pb}$ (II) ions was reached at $60 \mathrm{ppm}$; all the available adsorption sites have been captured. However, above this concentration, the \% uptake become decreasing because of adsorbate overloading which is exceed the maximum capacity of the exact used dose of the adsorbent.

\section{c. Effect of Temperature}

Temperature plays a significant role in the dynamic uptake of metal ions, and the transformation of surface complexation structures [26]. Three consecutive steps were involved in the removal of metal ions on kaolinite. First, the metal ion migrated from the bulk liquid phase to the outer surface of kaolinite particles (film diffusion). Secondly, the metal ion moved within the micro- and macro-pores of kaolinite particles (pore diffusion). Thirdly, the reaction of metal ionkaolinite species took place on the surface.

It can be seen from Figure 3 that the $\%$ uptake of $\mathrm{Pb}$ (II) increases as the temperature of the solution is increased. This increase continued up to reach the maximum adsorption capacity of the exact used dose of kaolinite. Kaolinite surface charge is also a function of temperature, surface charge becomes more negative with increasing temperature [27], so the affinity of the kaolinite surface for $\mathrm{Pb}$ (II) ions will be increased. As well as, the tendency for the $\mathrm{Pb}$ (II) ions to move from the liquid phase to the solid phase of the kaolinite clay with an increase in temperature of the solution.

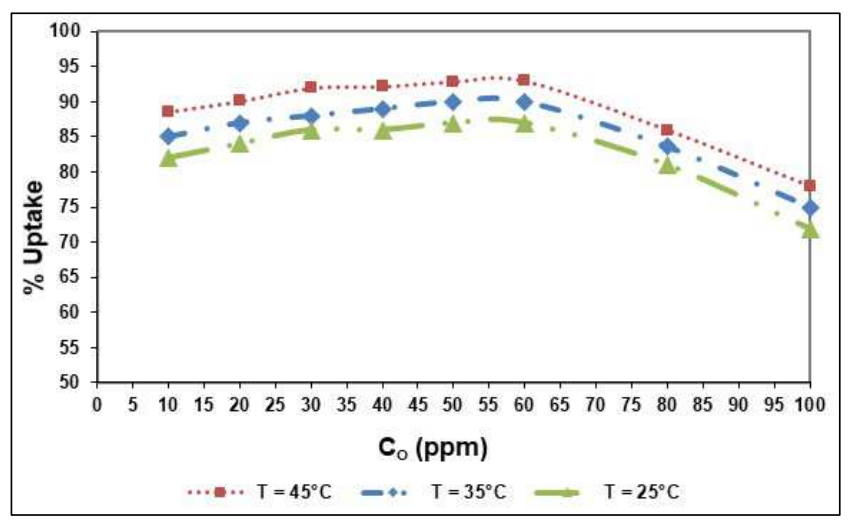

Figure 3. Effect of temperature on the adsorption of $\mathrm{Pb}$ (II) onto unmodified kaolinite clay at $p H$ (5).

The \% uptake of $\mathrm{Pb}$ (II) by unmodified kaolinite clay has in general small values which can be attributed to the fact that kaolinite is a well-packed structure; its particles are not easily broken down and the kaolinite layers are not easily separated. Hence, most adsorption activity occurs along the edges and outer surfaces of the structure. Therefore, modification with HA is necessitated.

Moreover, it's worth to mention that authors analyzed the sorption isotherms studies using Langmuir, Freundlich and $\mathrm{D}-\mathrm{R}$ isotherm models. The thermodynamic parameters also measured over a temperature range of 25,35 and $45^{\circ} \mathrm{C}$ confirming the feasibility, spontaneous and endothermic 
nature for adsorption on the kaolinite clay [28].

\subsubsection{Adsorption of Heavy Metal Ions onto HA Modified Kaolinite Clay by Batch Technique}

a. Effect of contact time

It was observed that initial adsorption of the metal ions was rapid, metal ions-clay interactions reached equilibrium in few hours (Figures 4 and 5). The greater density of adsorption sites e.g. carboxyl and phenolic hydroxyl sites on the clay minerals were quickly covered by metal ions.

The adsorption experiment was carried out with initial $\mathrm{pH} 5$, at $45^{\circ} \mathrm{C}$ for $(0.1 \mathrm{~g} \pm 0.1 \mathrm{mg})$ adsorbent dose and $10.0 \mathrm{~mL}$ of 100 ppm of metal ion.

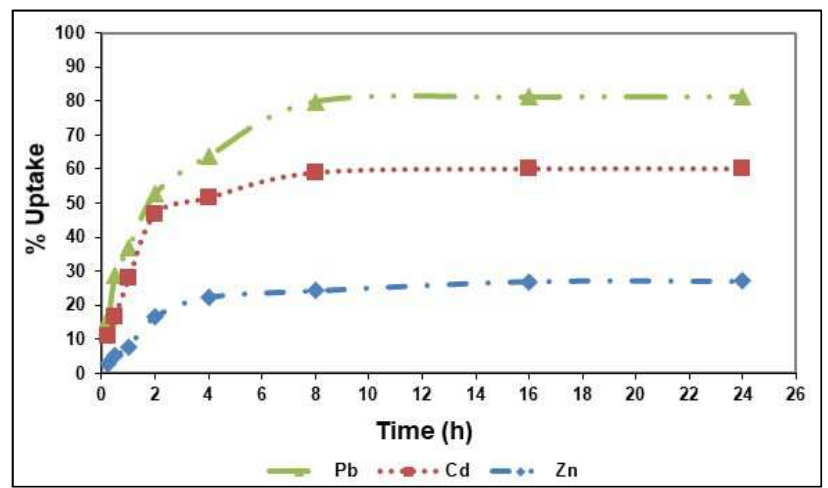

Figure 4. Effect of contact time on the amount of adsorption of Pb (II), Cd (II) and Zn (II) by FHA-kaolinite clay.

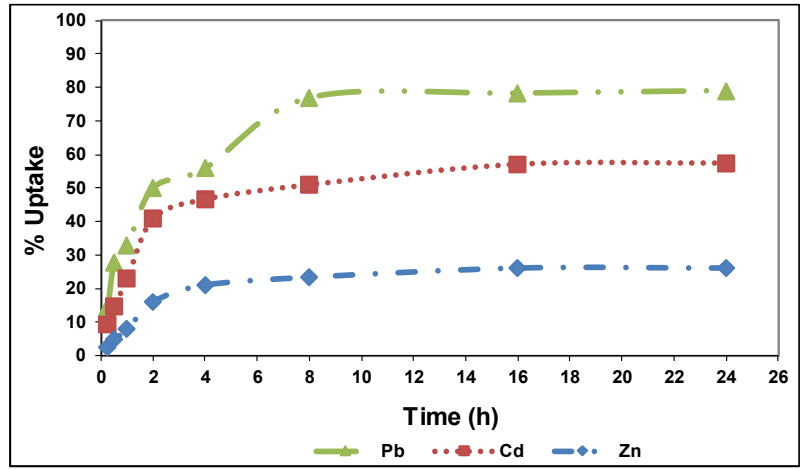

Figure 5. Effect of contact time on the amount of adsorption of Pb (II), Cd (II) and $\mathrm{Zn}$ (II) by KTD-kaolinite clay.
In comparison to the data for effect of contact time on the amount of adsorption of $\mathrm{Pb}$ (II), Cd (II) and $\mathrm{Zn}$ (II) by unmodified kaolinite clay, the data for modified kaolinite clay showed more \% uptakes. Which is refer to the increase in the adsorption sites, this is due to the presence of HA, where a lot of macro pores are available. As shown by measuring the total porosity of the clays using Mercury Porosimetry Analyzer instrument. The total porosity for the unmodified and FHA-kaolinite were $3.4 \%$ and $5.6 \%$, respectively. The reactivity and adsorption behavior will increase as the total porosity increases.

The surface area of unmodified and FHA-kaolinite clay was $\left(33.5 \mathrm{~m}^{2} / \mathrm{g}\right)$ and $\left(12.8 \mathrm{~m}^{2} / \mathrm{g}\right)$, respectively. The measurement was done using (Gemini VII) instrument according to Langmuir surface area method which is based on the isothermal adsorption of nitrogen, $\mathrm{N}_{2}$ gas can only capture or fill the micro and meso pores only; Gas Adsorption Isotherm used for small pore diameter analysis [29]. Depending on these measurements, the unmodified kaolinite clay has large number of pores in the range of micro and meso size, while the modified one has changes concern wider macro pores. It is obvious that the subsequent increase of the HA content has an effect on the average pore radius. This is a very a good evidence that kaolinite has been loaded with HA, on the other hand, structure of kaolinite porosity has been improved, and then enhance its adsorption capacity. Same results were obtained by Sokołowska and Sokołowski [30].

Adsorption of the metal ion at $(308.15 \mathrm{~K})$ was initially very fast. The initial uptake rate for the metal ion was very high as many adsorption sites were available for adsorption at the beginning of the process. As the sites were gradually filled up, the number of unoccupied sites becomes less, so adsorption became slow and the kinetics became more dependent on the rate at which the metal ionic species were transported from the exterior to the interior sites of the clay mineral particles or from the bulk of the solution to the clay surface. The linearity of the plots (Figure 6) of the pseudo-second-order model with $\mathrm{R}^{2}$ values greater than 0.90 for $\mathrm{Pb}$ (II).

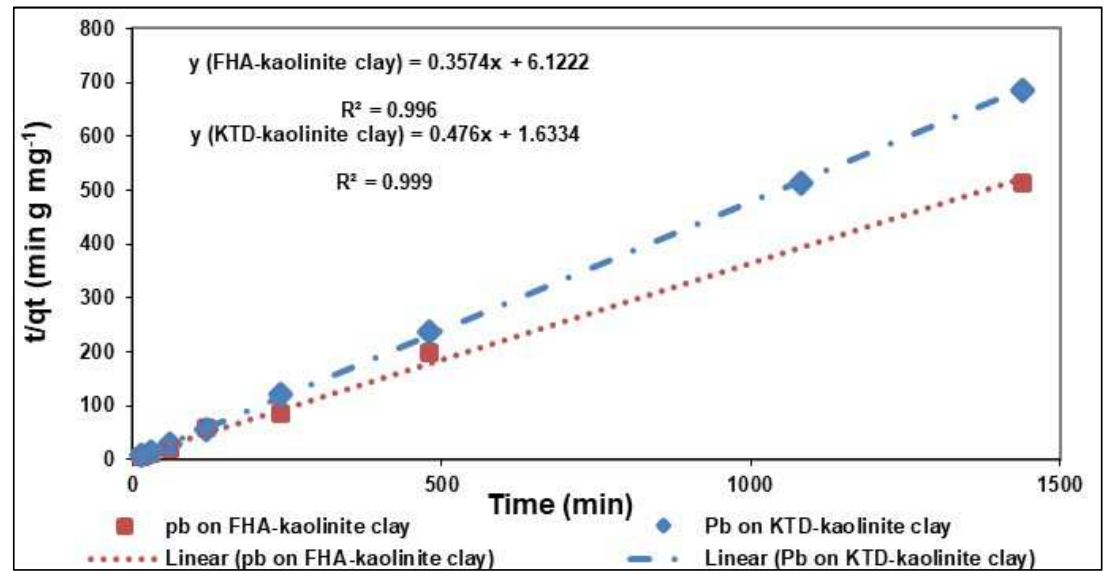

Figure 6. Pseudo-second-order kinetic plots for the adsorption of Pb (II) by FHA-kaolinite clay and KTD-kaolinite clay. 


\section{b. Effect of Adsorbent Dose}

Increase in adsorbent dose of FHA-kaolinite clay, from $(0.1-1.0) \mathrm{g} \pm 0.1 \mathrm{mg}$, at constant metal ion concentration and volume, resulted in a decrease in equilibrium adsorption capacity, qe (equation (1), Table 1). This will lead to unsaturation of adsorption sites through the adsorption process. Therefore, the equilibrium adsorption capacity of FHA-kaolinite clay is a function of its mass.

Table 1. Effect of varying FHA-kaolinite clay dose on the adsorption of $\mathrm{Pb}$ (II) at initial $\mathrm{pH}(5)$, initial concentration $(20 \mathrm{ppm})$, temperature $\left(35^{\circ} \mathrm{C}\right)$ and contact time (24 hrs).

\begin{tabular}{lll}
\hline Mass of FHA-kaolinite clay $(\mathbf{g})$ & $\mathbf{q}_{\mathbf{e}}(\mathbf{m g} / \mathbf{g})$ & \% Uptake \\
\hline 0.1 & 7.20 & 72.0 \\
0.2 & 4.70 & 94.0 \\
0.3 & 3.07 & 92.0 \\
0.5 & 1.84 & 92.0 \\
0.7 & 1.25 & 88.0 \\
1.0 & 0.84 & 84.0 \\
\hline
\end{tabular}

c. Effect of $\mathrm{pH}$

With reference to Tables (2 and 3), It is obvious that the higher the initial $\mathrm{pH}$ value the larger the adsorption capacity. At very low $\mathrm{pH}$, the concentrations of protons exceed that of the metal ions and the surface is most likely covered with $\mathrm{H}_{3} \mathrm{O}^{+}$ions. The metal ions can hardly compete with protons for the binding sites on the adsorbents. As $\mathrm{pH}$ increases, adsorption behavior can be explained based on a decrease in competition between proton and metal species for the surface sites. This results in a lower columbic repulsion of the adsorbing metal ion, and protons can leave the clay mineral surface and adsorbed HA making the sites available to the metal ion. The metal ions can bind to the clay surface through a mechanism like that of exchange interactions $\left(\mathrm{H}_{3} \mathrm{O}^{+} /\right.$metal ion (II)).

The higher carboxyl and phenol-containing fractions of FHA-kaolinite clay provided a greater density of sites available for complexation with metal ions.

Our results present in Tables (2 and 3) show that HAkaolinite clay increased the adsorption of metal ions at high pH. This observation explains metal adsorption by the combined action of aluminol, carboxyl and phenol groups which become activated at higher $\mathrm{pH}$ (because of being more like Lewis bases which have higher $\mathrm{pKa}$ ). Because $\mathrm{Pb}$ (II) exists as the unhydrolyzed ion (i.e., as the sole $\mathrm{Pb}$ (II)) at a higher $\mathrm{pH}$, it will react with aluminol/phenol sites which have a stronger basic character [31]. Moreover, it can be decided that FHA- kaolinite is better for adsorption of heavy metal ions than KTD- kaolinite. Therefore, a greater density of adsorption sites e.g. carboxyl and phenolic hydroxyl sites in FHA, enhance the adsorption of metal ions. Elemental analysis for both type of HA support this, it showed less percentage of oxygen in KTD, while the percentage of nitrogen is higher; it may be due to degradation of dead organic matter in the dam [32].

d. Effect of Temperature

The effect of temperature on adsorption is important not only because it impact the rate and extent of adsorption, but also because temperature dependence of adsorption provides information about possible adsorbate-adsorbent interaction.

The influence of temperature on metal ions adsorption is presented in Tables (2 and 3). The results indicate that the adsorption removal increased with increase of the solution temperature. It is possible that increasing temperature could have increased both film and pore diffusion as discussed early. Figures $7 \mathrm{a}$ and $\mathrm{b}$ present the plots of the $\mathrm{K}_{\mathrm{L}}$-Langmuir parameter against temperature for heavy metal ions adsorption on both modified kaolinite clay.

The $\mathrm{K}_{\mathrm{L}}$ parameter is the Langmuir equilibrium constant ( $\mathrm{L}$ $\mathrm{mg}^{-1}$ ) which gives information on both adsorption rate (compared to desorption rate of the system) and the heat of adsorption. For exothermic reactions, $\mathrm{K}_{\mathrm{L}}$ should decrease with increasing temperature of the system [33], and an opposite trend depicts endothermic reactions.

$$
\frac{C_{e}}{q_{e}}=\frac{1}{K_{L} q_{m}}+\frac{C_{e}}{q_{m}} \text { [34] }
$$

The values of $\mathrm{q}_{\mathrm{m}}$ and $\mathrm{K}_{\mathrm{L}}$ can be evaluated from the slope and the intercept of the linear plot of experimental data of $\mathrm{C}_{\mathrm{e}} / \mathrm{q}_{\mathrm{e}}$ versus $\mathrm{C}_{\mathrm{e}}$, equation 3 .

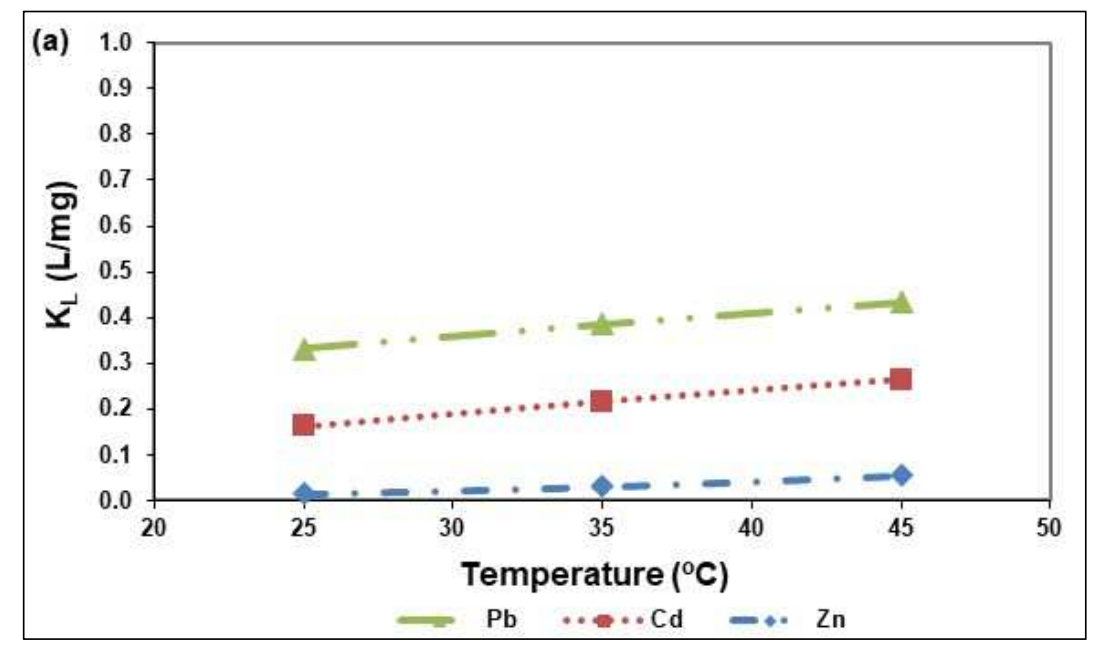




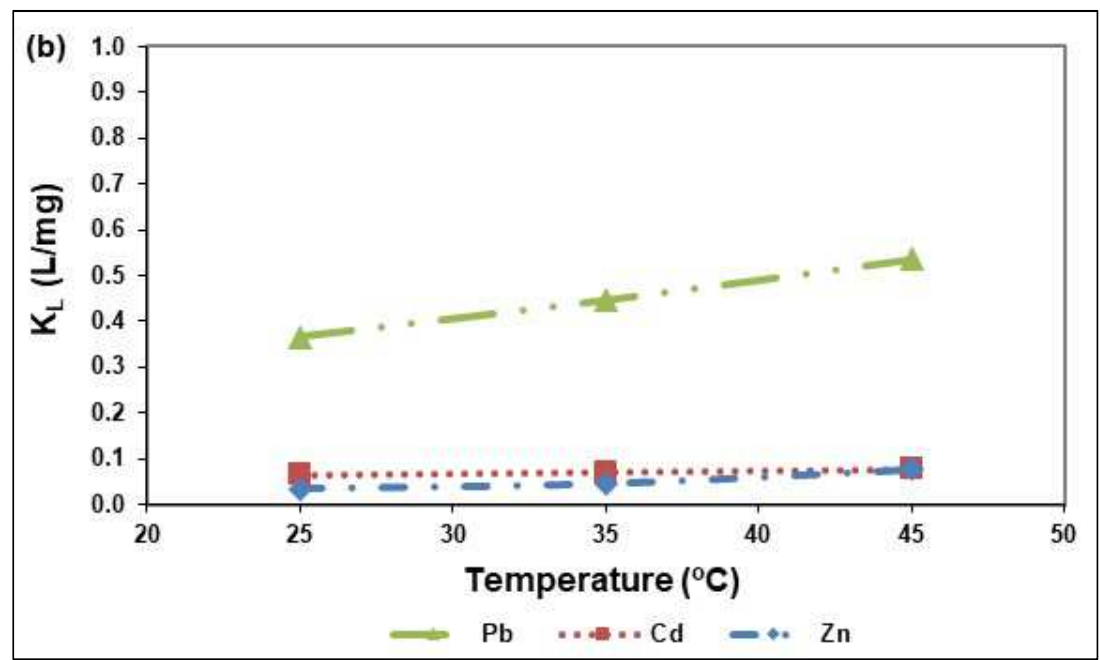

Figure 7. Langmuir parameters of Pb (II), Cd (II) and Zn (II) on (a) FHA-kaolinite clay and (b) KTD-kaolinite clay.

e. Effect of Initial Metal Ion Concentration

The percentage of metal ion uptake decreased with increasing initial metal ion concentration, The $\%$ uptake was studied in the initial $\mathrm{pH}$ range $4-6$, at different temperatures $25,35,45^{\circ} \mathrm{C}$ for $(0.2 \mathrm{~g} \pm 0.1 \mathrm{mg})$ adsorbent dose and $20.0 \mathrm{~mL}$ of different initial concentrations $10,20,30,40,50,60,80$ and 100 ppm at a constant ionic strength $(0.01 \mathrm{M})$ of $\mathrm{NaClO}_{4}$. As shown in Tables $(2$ and 3 ). This indicates a decrease in active sites on modified kaolinite clay as more metal ions are adsorbed.

Table 2. \% Uptake of Pb (II) by FHA-kaolinite clay.

\begin{tabular}{|c|c|c|c|c|c|c|c|c|c|c|}
\hline $\mathbf{T}\left({ }^{\circ} \mathrm{C}\right)$ & & 25 & & & 35 & & & 45 & & \\
\hline pH & & 4 & 5 & 6 & 4 & 5 & 6 & 4 & 5 & 6 \\
\hline \multirow{8}{*}{$\begin{array}{l}\text { Initial Concentration } \\
(\mathrm{ppm})\end{array}$} & 10.0 & 90.0 & 94.0 & 96.0 & 94.0 & 95.0 & 96.0 & 95.0 & 96.0 & 96.0 \\
\hline & 20.0 & 90.0 & 95.0 & 95.5 & 94.5 & 95.5 & 96.5 & 95.5 & 96.5 & 97.0 \\
\hline & 30.0 & 92.7 & 95.3 & 96.7 & 95.0 & 95.7 & 96.7 & 96.0 & 97.0 & 97.3 \\
\hline & 40.0 & 94.0 & 95.8 & 96.8 & 95.3 & 95.8 & 96.8 & 96.3 & 97.5 & 97.8 \\
\hline & 50.0 & 94.4 & 95.8 & 97.0 & 95.6 & 96.2 & 97.0 & 96.2 & 97.6 & 98.2 \\
\hline & 60.0 & 91.7 & 95.0 & 97.2 & 95.7 & 96.7 & 97.0 & 96.5 & 97.7 & 98.2 \\
\hline & 80.0 & 85.0 & 85.8 & 90.0 & 85.0 & 90.0 & 91.3 & 92.4 & 91.5 & 92.5 \\
\hline & 100.0 & 74.2 & 76.1 & 78.0 & 77.0 & 78.0 & 80.9 & 78.4 & 81.3 & 84.7 \\
\hline
\end{tabular}

Table 3. \% Uptake of Pb (II) by KTD-kaolinite clay.

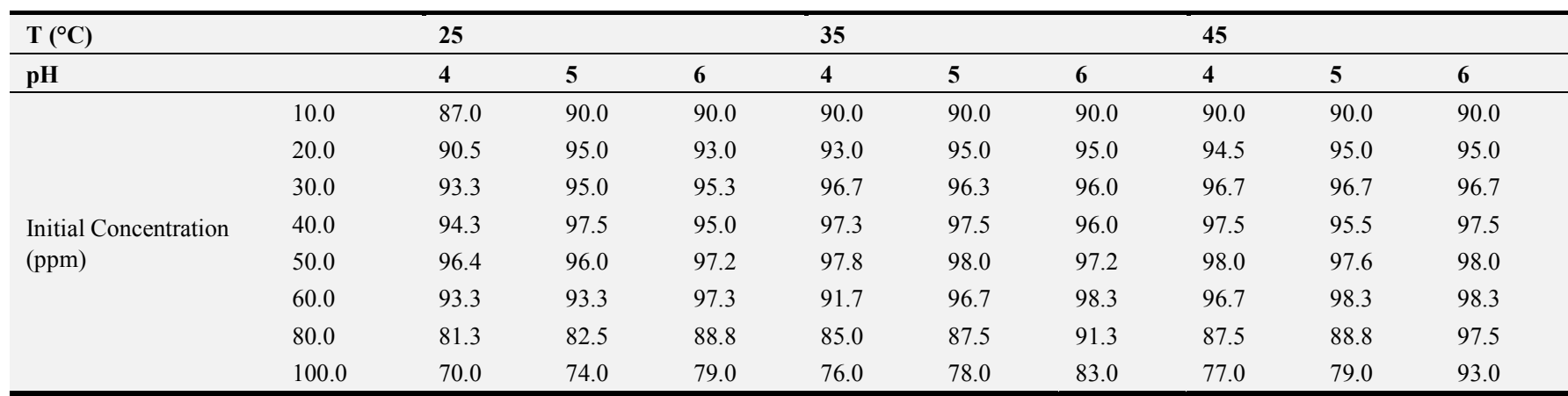

\subsubsection{Comparison Between Modified and Unmodified Kaolinite Clay Using Batch Technique}

From Tables (2 and 3), it was observed that modification of kaolinite clay enhanced adsorption of all metal ions. Moreover, FHA- kaolinite is better adsorbent than KTD- kaolinite. Figure 8 also supports this observation. Two factors may be responsible for the enhancement of adsorption of metal ions. Firstly, HA-coated kaolinite clay has a greater density of adsorption sites with negative charge on the clay's surface. Secondly, the adsorbed HA fractions can profoundly alter the surface charge, and contribute to the electrostatic attraction between kaolinite clay and metal ions, because of their negative charge. The enhancement of HA loaded on kaolinite clay would lead to an increase in metal adsorption abilities in the aqueous phase and form stable metal ions-HA complexes and diminish their precipitation. 


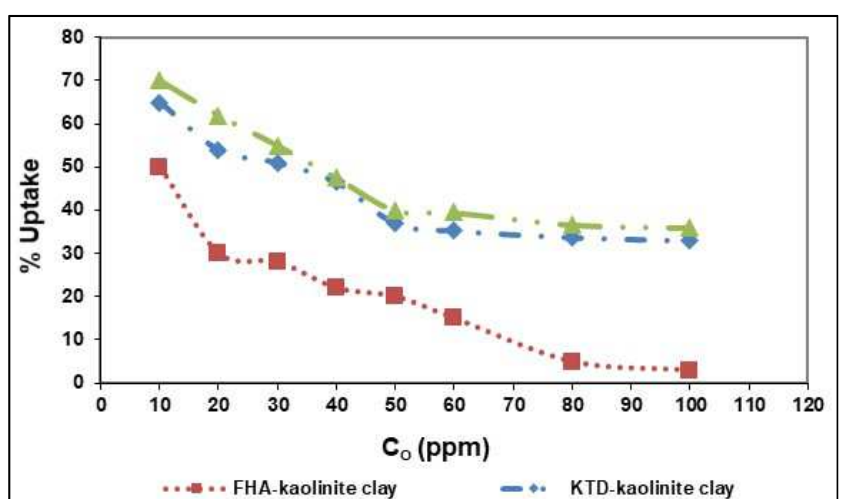

Figure 8. Comparison between unmodified and modified kaolinite clay adsorption of $\mathrm{Cd}$ (II) at $\mathrm{pH}(4)$ and $35^{\circ} \mathrm{C}$.

\subsection{Column Technique}

\subsubsection{Adsorption Experiments}

The percent of uptake for metal ions adsorbed onto unmodified and modified kaolinite clay using column technique are represented in Figures (9, 10, and 11). The metal ions showed higher affinity and higher adsorption capacity for the modified kaolinite clay than unmodified clay. The adsorption of the metal ions by both modified kaolinite clay followed the order: $\mathrm{Pb}>\mathrm{Cd}>\mathrm{Zn}$, which is the same order of the metal ions in the batch techniques.

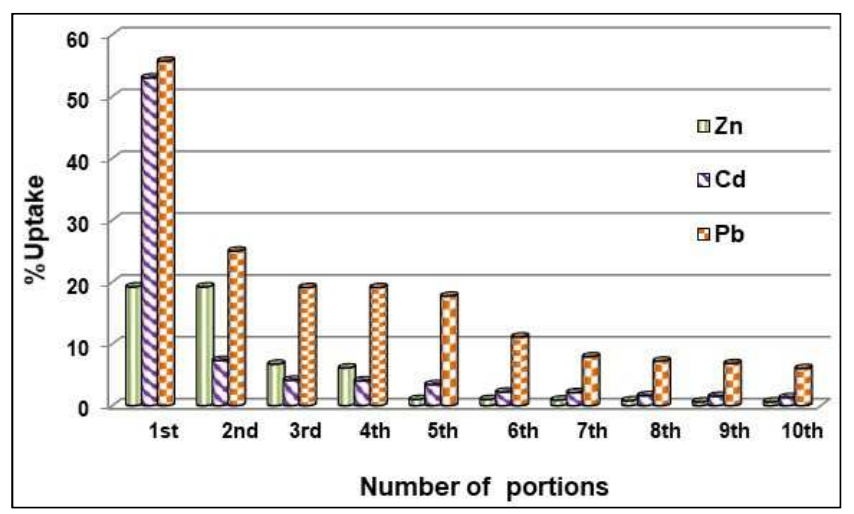

Figure 9. \% Uptake of metal ions by FHA-kaolinite clay using column technique.

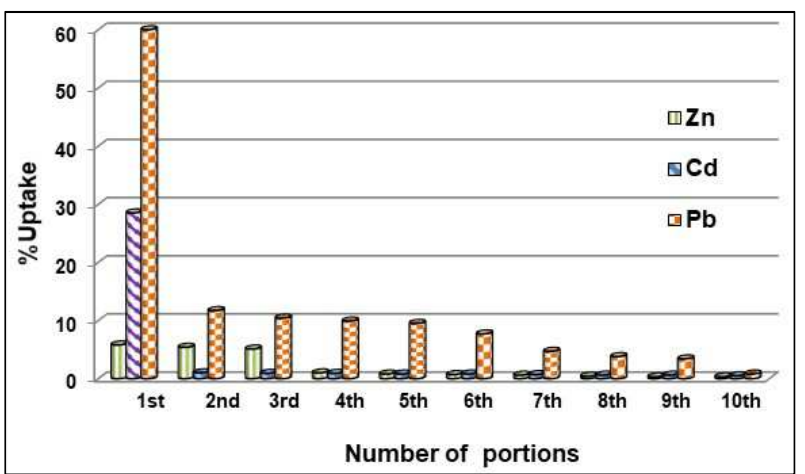

Figure 10. \% Uptake of metal ions by KTD-kaolinite clay using column technique.

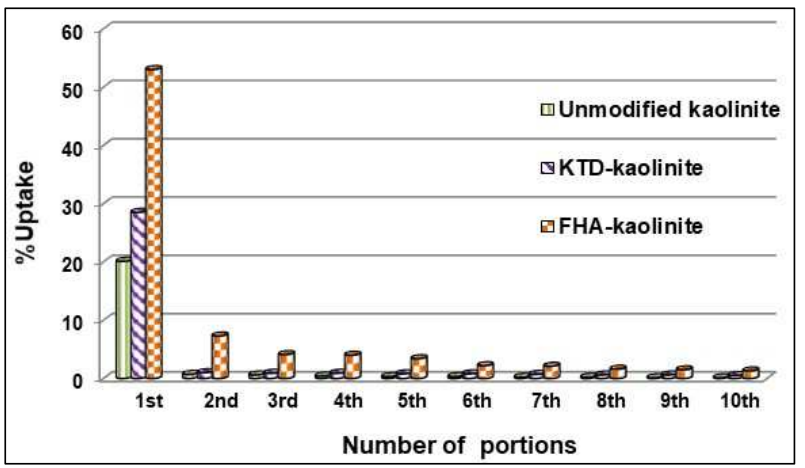

Figure 11. \% Uptake of Cd (II) by unmodified and both modified kaolinite clay using column technique.

From Figures (9 and 10), FHA-kaolinite clay again is better for adsorption of heavy metal ions than KTD-kaolinite clay. Therefore, a greater density of adsorption sites available in FHA, as affirmed. On the other hand, Figure 11 shows that modified kaolinite clay by HA is better for adsorption of heavy metal ions than unmodified kaolinite clay. This result agrees with that obtained by batch experiment.

\subsubsection{Desorption Experiments}

Desorption of adsorbed $1000 \mathrm{ppm}$ of $\mathrm{Pb}$ (II), Cd (II) and Zn (II) from the adsorption sites on the surface of the modified kaolinite clay sample showed that $>90 \%$ of metal ions adsorbed onto modified kaolinite clay samples were released. The collected elute was analyzed and the results are expressed as percent recovery and shown in Table 4.

Table 4. Desorption of metal ions adsorbed onto FHA and KTD-kaolinite clay.

\begin{tabular}{|c|c|c|c|c|c|c|c|c|c|c|}
\hline \multicolumn{6}{|c|}{ FHA-kaolinite clay } & \multicolumn{5}{|c|}{ KTD-kaolinite clay } \\
\hline \multirow[b]{2}{*}{ Eluting agent } & \multicolumn{5}{|c|}{ \% Recovery } & \multicolumn{5}{|c|}{ \% Recovery } \\
\hline & $1^{\text {st }} 10 \mathrm{ml}$ & $2^{\text {nd }} 10 \mathrm{ml}$ & $3^{\text {rd }} 10 \mathrm{ml}$ & $4^{\text {th }} 10 \mathrm{ml}$ & $\begin{array}{l}\text { \% Cumulative } \\
\text { recovery }\end{array}$ & $1^{\text {st }} 10 \mathrm{ml}$ & $2^{\text {nd }} 10 \mathrm{ml}$ & $3^{\text {rd }} 10 \mathrm{ml}$ & $4^{\text {th }} 10 \mathrm{ml}$ & $\%$ Cumulative recovery \\
\hline $0.1 \mathrm{M} \mathrm{HNO}_{3}$ & 56.89 & 29.61 & 5.64 & 4.56 & 96.70 & 81.95 & 5.74 & 5.17 & 2.87 & 95.73 \\
\hline $0.1 \mathrm{M} \mathrm{HNO}_{3}$ & 48.32 & 39.01 & 11.43 & 0.62 & 99.38 & 88.95 & 6.52 & 3.12 & 0.28 & 98.87 \\
\hline 1M EDTA & 42.06 & 39.75 & 7.31 & 5.70 & 94.83 & 54.90 & 36.27 & 1.96 & 0.49 & 93.63 \\
\hline
\end{tabular}

Both modified kaolinite clay can be desorbed of metal ions completely after the use of $40 \mathrm{~mL}$ of eluting agent.

\subsubsection{Regeneration Experiments}

It was found that metal ions were adsorbed onto both adsorbents when both adsorbents were reused in repeated cycles of adsorption of metal ions. This may be attributed to nitric acid used for desorption, causing the adsorbents to be protonated so they can adsorb again and still be efficient. 
Table 5. Reloading metal ions onto FHA and KTD - kaolinite clay after desorption process.

\begin{tabular}{|c|c|c|c|c|c|c|c|}
\hline \multicolumn{4}{|c|}{ FHA-Kaolinite Clay } & \multicolumn{4}{|c|}{ KTD-Kaolinite Clay } \\
\hline \multirow[b]{2}{*}{ Metal Ion } & \multirow[b]{2}{*}{ Initial Conc. (ppm) } & \multicolumn{2}{|c|}{ Loaded Conc. (ppm) } & \multicolumn{4}{|c|}{ Loaded Conc. (ppm) } \\
\hline & & $1^{\text {st }} 10 \mathrm{ml}$ & $2^{\text {nd }} 10 \mathrm{ml}$ & $\begin{array}{l}\text { Cumulative Load (mg Metal Ion } \\
\text { (II) / 2g Clay) }\end{array}$ & $1^{\text {st }} 10 \mathrm{ml}$ & $2^{\text {nd }} 10 \mathrm{ml}$ & $\begin{array}{l}\text { Cumulative Load (mg Metal Ion } \\
\text { (II) / } 2 \text { g Clay) }\end{array}$ \\
\hline Zn (II) & 1000 & 65 & 18 & 1.66 & 123 & 23 & 2.92 \\
\hline $\mathrm{Cd}$ (II) & 1000 & 124 & 75 & 3.98 & 298 & 14 & 6.24 \\
\hline $\mathrm{Pb}$ (II) & 1000 & 189 & 100 & 5.78 & 559 & 374 & 18.66 \\
\hline
\end{tabular}

According to Table 5, a similar trend of selectivity sequence of metal ions towards modified kaolinite clay is shown for the reloading process; $\mathrm{Pb}$ (II) $>\mathrm{Cd}$ (II) $>\mathrm{Zn}$ (II). This mean that desorption process did not affect the modified kaolinite clay properties. However, KTD-kaolinite clay can be reloaded and reused with metal ions more than FHA-kaolinite clay for all metal ions.

\section{Conclusion}

Clearly, kaolinite clay modified by HA significantly enhanced the adsorption of metal ions. The Cd (II) adsorbed by natural kaolinite clay was $1 \mathrm{mg} / \mathrm{g}$, while the amount adsorbed by modified kaolinite clay was nearly $22 \mathrm{mg} / \mathrm{g}$, and the latter is almost twenty times as much as the natural one. The results were consistent with the previous studies about the adsorption of heavy metal ions onto clays [35, 36, 37]. It indicated that the adsorption sites on the kaolinite were largely increased by modification. Also, the metal ions adsorption is highly dependent of $\mathrm{pH}$, that is, the adsorbed metal ions increased with increasing $\mathrm{pH}$. Lastly, a column packed with both modified kaolinite has good metal ions capacity. It was found that of metal ions were adsorbed onto both adsorbents while reusing both adsorbent in repeated cycles of adsorption of metal ions.

\section{References}

[1] Xiaoyan Z.; Zhichao Z.; Xinrong L.; Chunjie Y.; Defects in structure as the sources of the surface charges of kaolinite, Applied Clay Science, 2016, 124-125, 127-136.

[2] Olaremu A., Physico-chemical characterization of akoko mined kaolin clay, journal of minerals and materials characterization and engineering, 2015, 3, 353-361.

[3] Adebowale, K. O. Unuabonah, I. E. and Owolabi, B. I., The effect of some operating variables on the adsorption of lead and cadmium ions on kaolinite clay. J. Hazard. Mater., 2006, 134 (1-3), 130-139.

[4] Hongfeng C., Luuk K., Juan X., Marcelo A., Wenfeng T., Mechanisms of soil humic acid adsorption onto montmorillonite and kaolinite, Journal of Colloid and Interface Science, 2017, 504, 457-467.

[5] Hizal, J. and Apak, R., Modeling of cadmium (II) adsorption on kaolinite-based clays in the absence and presence of humic acid. Applied Clay Science, 2006, 32 (3-4), 232-244.

[6] Baglieri A., Vindrola D., Gennari M., Negre M., Chemical and spectroscopic characterization of insoluble and soluble humic acid fractions at different $\mathrm{pH}$ values, Chemical and Biological Technologies in Agriculture, 2014, 1-9.

[7] Irshad A., Weqar A., Samiullah Q., Tokeer A., Synthesis and characterization of molecular imprinted nanomaterials for the removal of heavy metals from water, Journal of Materials Research and Technology, 2017, ARTICLE IN PRESS.

[8] Mukhopadhyay R., Manjaiah K. M., Datta S. C., Yadav R. K., Binoy S., Inorganically modified clay minerals: Preparation, characterization, and arsenic adsorption in contaminated water and soil, Applied Clay Science, 2017, 147, 1-10.

[9] Ndongo Kounou G., Ndi Nsami J., Belibi Belibi D. P., Kouotou D., Tagne G. M., Dina Joh D. D., Ketcha Mbadcam J., Adsorption of Zinc (II) ions from aqueous solution onto Kaolinite and Metakaolinite, Der Pharma Chemica, 2015, 7 (3), 51-58.

[10] Struijk M., Rocha F., Detellier C., Novel thio-kaolinite nanohybrid materials and their application as heavy metal adsorbents in wastewater, Applied Clay Science, 2017, 150, 192-201.

[11] Fida H., Guo S., Zhang G., Preparation and characterization of bifunctional Ti-Fe kaolinite composite for $\mathrm{Cr}$ (VI) removal, Journal of Colloid and Interface Science, 2015, 442, 30-38.

[12] Khoury H., Importance of Clay Minerals in Jordan Case Study: Volkonskoite as a Sink for Hazardous Elements of a High pH Plume, Jordan Journal of Earth and Environmental Sciences, 2014, 6 (3), 1- 10.

[13] Gregory N. S., Laurens K., Timothy S. G., Transitions in water harvesting practices in Jordan's rainfed agricultural systems: Systemic problems and blocking mechanisms in an emerging technological innovation system, Environmental Science \& Policy, 2017.

[14] Policy and Strategic Behaviour in Water Resource Management, Water scarcity, quality and environmental protection policies in Jordan, page 33-43.

[15] Khalili F., Humic and Fulvic Acids from Several Locations in Jordan. Dirasat, 1987, 14 (12), 151-162.

[16] Li, H. Sheng, G. Teppen, B. J. Johnston, C. T. and Boyd, S. A., Sorption and Desorption of Pesticides by Clay Minerals and Humic Acid-Clay Complexes, Soil Sci Soc Am J., 2003, 67 (1), $122-131$.

[17] Al-Essa K., Khalili F., Adsorption of Humic acid onto Jordanian Kaolinite Clay: Effects of Humic acid Concentration, $\mathrm{pH}$, and Temperature, Science Journal of Chemistry, 2017, ARTICLE IN PRESS.

[18] Ibrahim W., Hassan A., Azab A., Biosorption of toxic heavy metals from aqueous solution by Ulva lactuca activated carbon, Egyptian Journal of Basic and Applied Sciences, 2016, 3, 241249. 
[19] Min J., Xiao S., Yingxin Z., Wenfang Q., Yue W., Guanyi C., Zhenya Z., Effective adsorption of Cr (VI) on mesoporous Fe-functionalized Akadama clay: Optimization, selectivity, and mechanism, Applied Surface Science, 2015, 344, 2015, 128-136.

[20] Bohli T, Villaescusa I, Ouederni A, Comparative study of bivalent cationic metals adsorption $\mathrm{Pb}$ (II), Cd (II), Ni (II), and $\mathrm{Cu}$ (II) on olive stones chemically activated carbon, J Chem Eng Process Technol, 2013, 4:158-164.

[21] Ricordel S, Taha S, Cisse I, Dorange G, Heavy metals removal by adsorption onto peanut husks carbon: characterization, kinetic study and modeling, Sep Purif Technol, 2005, 24, 389401 .

[22] Rovshan M., Chin Pao H., Selective adsorption of oxyanions on activated carbon exemplified by Filtrasorb 400 (F400), Separation and Purification Technology, 2011, 77 (3), 294-300.

[23] Xiuyan Z., Xiangxin X., Wenming J., Study on adsorption of heavy metal ion in metallurgical wastewater by sepiolite, 2011 2nd International Conference on Environmental Science and Development. IPCBEE (2011), vol. 4 IACSIT Press, Singapore.

[24] Ming-qin J., Xiao-ying J., Xiao-Qiao L., Zu-liang C., Adsorption of $\mathrm{Pb}$ (II), Cd (II), $\mathrm{Ni}$ (II) and $\mathrm{Cu}$ (II) onto natural kaolinite clay, Desalination 252 (2010) 33-39.

[25] Au P., Leong Y., Surface chemistry and rheology of slurries of kaolinite and montmorillonite from different sources, KONA Powder and Particle Journal, 2016, 33, 17-32.

[26] Yang S., Sheng G., Tan X., Hu J., Du J., Montavon G., Wang X., Determination of $\mathrm{Ni}$ (II) uptake mechanisms on mordenite surfaces: a combined macroscopic and microscopic approach. Geochim Cosmochim Acta, 2011, 75:6520-6534.

[27] Cama J., Metz V., Ganor J., The effect of $\mathrm{pH}$ and temperature on kaolinite dissolution rate under acidic conditions, Geochimica et Cosmochimica Acta, 2002, 66 (22), 3913-3926.

[28] Al-Essa K., Khalili F., Sorption of Pb (II) Ions by Kaolinite Modified with Humic Acids, Journal of Environmental Science and Engineering A. 2016, 5:416-431.
[29] Largitte L, Pasquier R., A review of the kinetics adsorption models and their application to the adsorption of lead by an activated carbon. Chemical Engineering Research and Design, 2016, 109, 495-504.

[30] Sokołowska Z, Sokołowski S., Influence of humic acid on surface fractal dimension of kaolin: analysis of mercury porosimetry and water vapour adsorption data, Geoderma, $1999,88,233-249$.

[31] Folasegun A. D., Kovo G. A., Simultaneous adsorption of Ni (II) and Mn (II) ions from aqueous solution unto a Nigerian kaolinite clay, Journal of Materials Research and Technology, 2014, 3 (2), 129-141.

[32] Khalili, F. and Ajjouri, H., X-ray Diffraction Studies on Jordanian Humic and Fulvic Acids. Dirasat, 1987, 14 (12), 163-166.

[33] Faust, S. D. and Aly, O. M. (1987), Adsorption Processes for Water Treatment, First edition, Boston, Butterworth Publishers.

[34] Tashauoei, H. R. Attar, H. M. Amin, M. M. Kamali, M. Nikaeen, M. and Dastjerdi, V., Removal of cadmium and humic acid from aqueous solutions using surface modified nanozeolite A. International Journal of Environmental Science and Technology, 2010, 7 (3), 497-508.

[35] Bhattacharyya, K. and Gupta, S., Kaolinite, montmorillonite, and their modified derivatives as adsorbents for removal of $\mathrm{Cu}$ (II) from aqueous solution. Separation and Purification Technology, 2006, 50 (3), 388-397.

[36] Jiang, M. Q. Wang, Q. P. Jin, X. Y. and Chen, Z. L., Removal of $\mathrm{Pb}$ (II) from aqueous solution using modified and unmodified kaolinite clay. Journal of Hazardous Materials, 2009, 170 (1), 332-339.

[37] Amer, M. Khalili, F. and Awwad, A., Adsorption of lead, zinc and cadmium ions on polyphosphate-modified kaolinite clay. Journal of Environmental Chemistry and Ecotoxicology, 2010, 2 (1), 001-008. 